\title{
OPTIMALISASI PEMANFAATAN LAHAN SEMPIT MENGGUNAKAN TEKNIK VERTIKULTUR MIKROHIDROPONIK DENGAN MEDIA TANAM DAN PUPUK AB MIX PADA TANAMAN SELADA (Lactuca sativa L.)
}

\author{
Oleh : \\ Zulkifli \\ Ida Zulfida \\ E-mail corresponding : zulkiflitanjung@gmail.com \\ E-mail Author : idazulfida@gmail.com \\ Universitas Pembinaan Masyarakat Indonesia
}

\begin{abstract}
ABSTRAK
Penelitian ini bertujuan untuk mengetahui pengaruh teknik budidaya vertikultur Mikrohidroponik dengan menggunakan media tanam dan pemakaian pupuk AB Mix pada tanaman Selada serta untuk mengetahui peranan teknik budidaya vertikultur mikrohidroponik sebagai solusi dalam mengatasi permasalahan lahan sempit khususnya di daerah perkotaan. Adapun parameter yang diamati adalah tinggi tanaman $(\mathrm{cm})$, jumlah daun (helai) dan berat tanaman saat panen (g). Penelitian ini merupakan percobaan lapangan yang dilaksanakan pada bulan Mei sampai Juni 2021. Pada penelitian ini menggunakan teknik mikrohidroponik dengan sistem pertanaman secara vertikultur dengan menggunakan benih selada New grand rapids. Penelitian ini dilakukan dengan menggunakan Rancangan Acak Lengkap (RAL) dengan Faktor I : Larutan AB Mix yang terdiri dari dua taraf yaitu AB0 : 500 ppm; AB1 : 750 ppm; dan Faktor II : Media tanam yang terdiri dari dua taraf yaitu M0 : Arang sekam ; M1 :Cocopeat. Penelitian ini dilaksanakan di Rumah kaca Fakultas Pertanian Universitas Pembinaan Masyarakat Indonesia Medan. Dari hasil penelitian setelah dianalisis secara statistik, pengaruh interaksi pengaplikasian Larutan AB Mix dan Media tanam berpengaruh tidak nyata dengan $\mathrm{F}$ hitung $<\mathrm{F}$ tabel terhadap tinggi tanaman $(\mathrm{cm})$ pada umur 1 mst, 2 mst, 3 mst, 4 mst, 5 mst serta jumlah daun (helai) pada umur 1 mst; dan berpengaruh nyata dengan $\mathrm{F}$ hitung $>\mathrm{F}$ tabel terhadap jumlah daun (helai) pada umur $2 \mathrm{mst}$, 3 mst, 4 mst, 5 mst, serta berat tanaman saat panen (g). Dari hasil penelitian secara deskriptif, teknik pertanaman secara vertikultur mampu mengatasi permasalahan lahan sempit yaitu dengan volume area pertanaman yaitu $300 \mathrm{~cm} \times 50 \mathrm{~cm} \times 120 \mathrm{~cm}$ mampu dibudidayakan tanaman selada secara hidroponik dengan sistem DFT (Deep Flow Tehnique) sebanyak 96 tanaman dengan jarak antar tanaman $15 \mathrm{~cm}$ dan jarak antar pipa dalam instalasi $30 \mathrm{~cm}$ dengan 2 instalasi.
\end{abstract}

Kata kunci : Selada, Mikrohidroponik, Vertikultur, Lahan Sempit..

\begin{abstract}
This research is a field experiment carried out from May to June 2021. In this study using a microhydroponic technique with a vertical cropping system using New grand rapids lettuce seeds. This research was conducted using a completely randomized design (CRD) with Factor I: AB Mix solution consisting of two levels, namely AB0: 500 ppm; AB1:750 ppm; and Factor II: Planting media consisting of two levels,
\end{abstract}

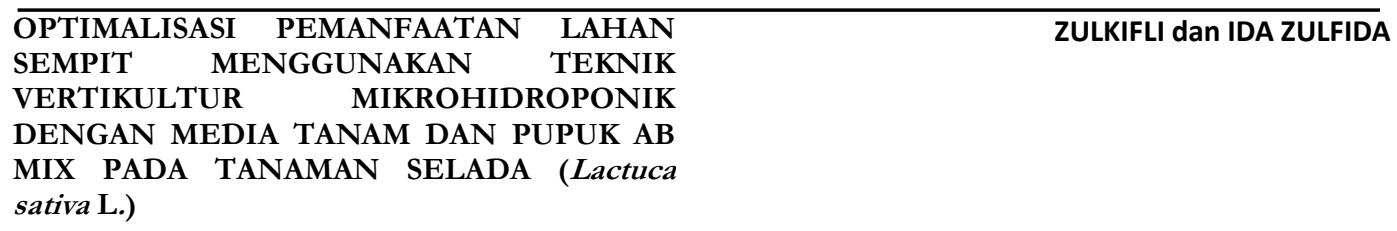


namely M0: busk charcoal; M1: Cocopeat. This research was conducted in the greenhouse of the Faculty of Agriculture, Universitas Pembinaan Masyarakat Indonesia Medan. From the results of the study after statistical analysis, the interaction effect of the application of $A B$ Mix Solution and planting media had no significant effect with $F$ count $<F$ table on plant height (cm) at the age of 1 mst, 2 mst, 3 mst, 4 mst, 5 mst and the number of leaves (strands) at the age of $1 \mathrm{mst}$; and significantly affected by calculated $\mathrm{F}$ count $>\mathrm{F}$ table on the number of leaves (strands) at the age of 2 weeks, 3 weeks, 4 weeks, 5 weeks, and plant weight at harvest (g). From the results of descriptive research, vertical planting techniques are able to overcome the problem of narrow land, namely with a volume of planting area that is $300 \mathrm{~cm} \times 50 \mathrm{~cm} \times 120 \mathrm{~cm}$, lettuce plants can be cultivated hydroponically with the DFT system (Deep Flow Tebnique) as many as 96 plants with a distance between plants of $15 \mathrm{~cm}$ and a distance of $15 \mathrm{~cm}$ between plants. between pipes in a $30 \mathrm{~cm}$ installation with 2 installations.

Keywords : Lettuce, Microbydroponics, Verticulture, Narrow Land.

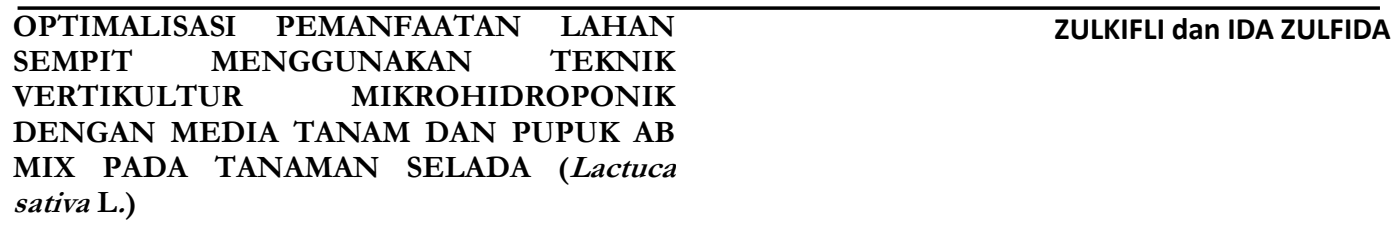




\section{PENDAHULUAN}

Seiring dengan meningkatnya jumlah penduduk di Indonesia, permintaan pasar pada sektor pangan juga akan semakin meningkat (Roidah 2014 dalam Sari E, 2016). Namun, hal tersebut tidak diikuti dengan ketersediaan lahan pertanian yang cukup. Oleh karena itu perlu pengembangan teknologi untuk mencukupi kebutuhan pangan dalam negeri salah satunya dengan teknik Hidroponik, sehingga masalah keterbatasan lahan terutama di daerah perkotaan dapat diatasi dan diminimalisir.

Selada (Lactuca sativa L.) merupakan salah satu jenis tanaman yang bisa dibudidayakan melalui teknik hidroponik. Data permintaan Selada hijau menurut YUM Organik Farm tahun 2019 sebesar 2.708 kg sedangkan produksi selada hijau sebesar $1.857 \mathrm{~kg}$. Dari data tersebut terlihat bahwa selisih antara permintaan dan produksi selada hijau sebesar $851 \mathrm{~kg}$, sehingga perlu pengembangan usaha dalam budidaya tanaman selada untuk memenuhi permintaan yang tinggi (Wulandari dkk. 2013). Menurut Kementrian Pertanian (2018), bahwa pada tahun tahun 2017 ekspor sayuran seperti kubis, buncis dan selada air dapat menempati tiga urutan tertinggi yaitu 132.878 ton dan pada tahun 2019 tercatat ada ekspor 1.500.000 kilogram dan adanya impor sayuran selada tahun 2019 dengan angka menyentuh 171.000 kilogram (Badan Pusat Statistik, 2019).

Nurwati, dkk (2015) menyatakan bahwa pemanfaatan pekarangan sempit bisa dijadikan sebagai salah satu alternatif untuk menangkal kerawanan pangan dalam keluarga. Pemanfaatan pekarangan sempit dianjurkan menggunakan sistem vertikultur dengan mengembangkan sistem pertanian dari kebiasaan bertanam secara konvensional ke sistem pertanaman secara hidroponik yang dapat dilakukan secara vertikal. Pada sistem pertanaman secara konvensional biasanya dilakukan dimana tanah adalah unsur utama dalam terlaksananya teknik budidaya sedangkan dalam teknik budidaya tanaman secara hidroponik tidak lagi berpatokan pada keadaan tanah atau lahan yang harus luas melainkan menggunakan instalasi khusus yang hemat area dengan memanfaatkan cairan ditambah nutrisi yang dapat mendukung pertumbuhan tanaman budidaya tanaman dapat dilakukan secara optimal. Teknik budidaya hidroponik membuat lingkungan sekitar tanaman dapat dikontrol (Saito et al. 2013) .

Penerapan teknik hidroponik jika dikombinasikan dengan sistem penanaman secara vertikultur maka permasalahan akan ketersediaan lahan dapat diatasi dengan baik. Penanaman dengan sistem pertanaman vertikultur merupakan usaha budidaya secara vertikal sehingga sering juga disebut sebagai vertikal farming. 


\section{METODE PENELITIAN}

Penelitian ini dilaksanakan di Green House Fakultas Pertanian Universitas Pembinaan Masyarakat Indonesia Medan, Jl.Balai desa Marindal II, Amplas. Penelitian ini dilaksanakan mulai pada bulan Mei sampai Bulan Juni.

Bahan yang digunakan dalam penelitian ini adalah benih tanaman Selada (Lactuca sativa L. Var. New Grand Rapids), Arang Sekam, Cocopeat, Rockwool, air, cairan atau nutrisi berupa zat $\mathrm{AB}$ mix, dan bahan-bahan lain yang mendukung dalam pelaksanaan penelitian ini. Sedangkan Alat yang digunakan dalam penelitian ini terdiri dari pisau, meteran, handsprayer, timbangan elekrik, alat tulis, ember, gayung, gunting, Pipa PVC, Knee T,L, dan Dop, Pompa air akuarium, Boks container (Bak Penampung), Bak Penyemaian, botol aqua $220 \mathrm{ml}$, Pipa PVC 3 inc, dan alat-alat lain yang mendukung pelaksanaan penelitian ini.

Penelitian ini dilakukan dengan menggunakan metode Rancangan Acak Lengkap (RAL) dan Analisis Kualitatif Pemanfaatan Lahan Sempit.

Tabel 1. Metode Rancangan Acak Lengkap.

\begin{tabular}{llcc}
\hline \multicolumn{1}{c}{ Faktor } & \multicolumn{1}{c}{ Banyaknya Taraf } & \multicolumn{2}{c}{ Taraf } \\
\hline AB Mix & Dosis $: 2$ taraf & $500 \mathrm{ppm}$ & $750 \mathrm{ppm}$ \\
Media Tanam & Jenis $: 2$ taraf & Arang Sekam & Cocopeat \\
\hline
\end{tabular}

Jumlah kombinasi perlakuan adalah $2 \times 2=4$ kombinasi yaitu :

Tabel 2. Kombinasi Perlakuan.

\begin{tabular}{ccc}
\hline \multirow{2}{*}{ Larutan Nutrisi AB Mix (AB) } & \multicolumn{2}{c}{ Media Tanam (M) } \\
\cline { 2 - 3 } & M0 & M1 \\
\hline AB0 & AB0M0 & AB0M1 \\
AB1 & AB1M0 & AB1M1 \\
\hline
\end{tabular}

Jadi, untuk ketelitian dalam penelitian ini dilakukan ulangan sebanyak 3 kali, sehingga diperoleh 12 unit percobaan.

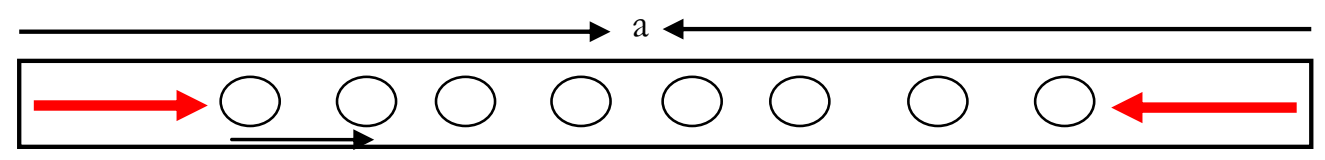

Keterangan :

$\begin{array}{ll}\text { a } \quad \text { Panjang Pipa } & =149 \mathrm{~cm} \\ \mathrm{~b} \quad \text { : Jarak Tanam } & =15 \mathrm{~cm} \\ \text { : Lubang Tanam (Diameter } 7 \mathrm{~cm} \text { ) } & \\ \text { Panjang pipa percobaan } & =7 \mathrm{~cm} \\ \text { Jarak tanam antar tanaman } & : 149 \mathrm{~cm} \\ \text { Jumlah unit Percobaan } & : 15 \mathrm{~cm} \\ \text { Jumlah tanaman / unit } & : 12 \text { unit } \\ \text { Jumlah tanaman seluruhnya } & : 8 \text { tanaman } \\ \text { Jumlah tanaman sampel / unit } & : 96 \text { tanaman } \\ \text { Jumlah tanaman sampel seluruhnya } & : 4 \text { tanaman } \\ \text { Juman talang } & : 48 \text { tanaman }\end{array}$




\section{Metode Analisis}

Metode analisis data adalah Rancangan Acak Lengkap (RAL) dengan model linear :

$$
\begin{aligned}
& Y_{i j}=\mu+T_{i}+\varepsilon_{i j} \quad i=1,2, \ldots, t \\
& \mathrm{j}=1,2, \ldots, \mathrm{n}
\end{aligned}
$$

Yij = nilai pengamatan pada perlakuan ke $\mathrm{i}$, ulangan ke $\mathrm{j}$

$\mu=$ nilai tengah umum

$\mathrm{Ti}=$ pengaruh perlakuan ke $\mathrm{i}$

$\varepsilon_{i j}=$ pengaruh acak (kesalahan percobaan) pada perlakuan ke I dan ulangan ke $\mathrm{j}$

$\mathrm{t}$ = banyaknya perlakuan

$\mathrm{n}$ = banyaknya ulangan

\section{Pelaksanaan Penelitian}

Pelaksanaan penelitian meliputi : Persemaian (menggunakan media Rockwool. Persemaian dilakukan selama $14 \mathrm{hss}$ ); Penanaman (dipindahkan ke media tanaman dengan media tanam arang sekam dan cocopeat dan diletakan dalam instalasi hidroponik); Pengaplikasian nutrisi (untuk dosis pertama yaitu 500 ppm dan dosis kedua yaitu 750 ppm, setiap minggunya ditambah 100 ppm); dan Pemeliharaan tanaman (kontrol lingkungan dan nutrisi tanaman tiap minggunya).

\section{Variabel Yang Diamati}

Adapun variabel yang diamati dalam penelitian ini yaitu : tinggi tanaman $(\mathrm{cm})$, jumlah daun (helai) dan berat tanaman saat panen (g). Untuk pengamatan tinggi tanaman (cm) dan jumlah daun (helai) dilakuan mulai pada umur 1 mst, 2 mst, 3 mst, 4 mst dan 5 mst.

\section{HASIL DAN PEMBAHASAN}

\section{Tinggi Tanaman $(\mathrm{Cm})$}

Pengamatan tinggi tanaman dilakukan dari pangkal tumbuh tanaman pada permukaan media tanam sampai pada ujung daun tertinggi. Pengamatan tinggi tanaman dimulai pada saat tanaman berumur 1 mst, 2 mst, 3 mst, 4 mst, dan 5 mst.

Berdasarkan uji statistik, pengaruh aplikasi Larutan AB Mix dan Media tanam berpengaruh tidak nyata terhadap tinggi tanaman $(\mathrm{cm})$ pada umur $1 \mathrm{mst}, 2 \mathrm{mst}, 3$ mst, 4 mst dan 5 mst.

\section{Jumlah Daun (Helai)}

Dari hasil uji statistik pengaruh Pengaplikasian Larutan AB Mix dan Media tanam berpengaruh tidak nyata terhadap jumlah daun (helai) pada umur $1 \mathrm{mst}, 2 \mathrm{mst}$, 3 mst, 4 mst dan 5 mst. Interaksi Pengaplikasian Larutan AB Mix dan Media tanam

\begin{tabular}{lrr}
\hline OPTIMALISASI PEMANFAATAN & LAHAN & ZULKIFLI dan IDA ZULFIDA \\
SEMPIT MENGGUNAKAN & TEKNIK & \\
VERTIKULTUR & MIKROHIDROPONIK & \\
DENGAN MEDIA TANAM DAN PUPUK AB & \\
MIX PADA TANAMAN & SELADA & (Lactuca \\
sativa L.) &
\end{tabular}


berpengaruh tidak nyata terhadap jumlah daun (helai) pada umur $1 \mathrm{mst}$, dan berpengaruh sangat nyata terhadap jumlah daun (helai) pada umur 2 mst, 3 mst, 4 mst dan 5 mst.

\section{Berat Tanaman (g)}

Berat tanaman dihitung dengan menimbang tanaman yang diambil dari tanaman sampel pada saat panen dalam satuan gram (g). Data berat tanaman saat panen serta daftar sidik ragamnya disajikan pada lampiran 24 dan lampiran 25. Dari hasil analisis sidik ragam diketahui bahwa pengaruh pengaplikasian Larutan AB Mix dan Media tanam berpengaruh sangat nyata terhadap berat tanaman dengan nilai $\mathrm{F}$ hitung $>$ F tabel pada taraf $5 \%$.

\section{PEMBAHASAN}

\section{Pengaruh Pengaplikasian Larutan AB Mix Terhadap Pertumbuhan dan} Produksi Tanaman Selada (Lactuca sativa L. Var. New Grand Rapids)

Dari hasil penelitian yang dilakukan dan setelah dianalisis secara statistik diperoleh bahwa perlakuan pengaruh pengaplikasian Larutan AB Mix dan Media tanam berpengaruh tidak nyata terhadap tinggi tanaman $(\mathrm{cm})$ pada umur $1 \mathrm{mst}, 2$ mst, 3 mst, 4 mst dan 5 mst, jumlah daun (helai) pada umur 1 mst, 2 mst, 3 mst, 4 mst, dan 5 mst, berat tanaman saat panen (g) pada umur 1 mst, 2 mst, 3 mst, 4 mst, dan 5 mst.

Peningkatan tinggi tanaman selada dipengaruhi oleh dosis dan penambahan Larutan AB Mix tiap minggunya. Pada tabel 1, 3, 5, 7, dan 9 menunjukkan bahwa tinggi tanaman dengan dengan perlakuan AB0 (Dosis 500 ppm dengan penambahan 100 ppm) pada umur 1 mst, 2 mst, 3 mst , 4 mst dan 5 mst memiliki tinggi tanaman lebih baik dibandingkan dengan perlakuan AB1 (Dosis 750 ppm dengan penambahan 100 ppm) pada umur 1 mst, 2 mst, 3 mst, 4 mst, dan 5 mst. Peningkatan jumlah daun sangat dipengaruhi oleh dosis dan interval pengaplikasian larutan nutrisi $\mathrm{AB}$ Mix. Pada tabel 11 menunjukan bahwasanya parameter tinggi tanaman pada perlakuan AB0 (Dosis 500 ppm dengan penambahan 100 ppm) pada umur 1 mst lebih baik dibandingkan dengan perlakuan AB1 (Dosis 750 ppm dengan penambahan 100 ppm), sedangkan pada umur 2 mst, 3 mst, 4 mst, dan 5 mst perlakuan $A_{1}$ Menunjukkan pengaruh jumlah daun (helai) yang lebih baik dibandingkan dengan $\mathrm{AB}_{0}$. 
Pengaruh Pengaplikasian Media Tanam Terhadap Pertumbuhan dan Produksi Tanaman Selada (Lactuca sativa L. Var New Grand Rapids).

Penunjang keberhasilan dari sistem budidaya hidroponik adalah media yang bersifat porous dan aerasi baik serta nutrisi yang tercukupi untuk pertumbuhan tanaman (Permatasari et al,. 2012).

Berdasarkan hasil penelitian menjukkan bahwa pengaplikasian media tanam $\mathrm{M}_{1}$ (cocopeat) dianggap lebih baik dibandingkan dengan $\mathrm{M}_{0}$ (arang sekam) terhadap parameter tinggi tanaman tanaman (cm), jumlah daun (helai) dan berat tanaman saat panen (g). Hal ini sesuai dengan hasil penelitian Zenita Y.M. \& E. Widaryanto (2019) menyatakan bahwa Media tanam cocopeat menunjukkan hasil yang terbaik dalam parameter panjang tanaman, jumlah daun, lebar kanopi tanaman, luas daun, bobot segar total dan bobot segar konsumsi dibandingkan dengan perlakuan media tanam arang sekam dan pasir.

\section{Pengaruh Interaksi Pengaplikasian Larutan AB Mix dan Media Tanam Terhadap Pertumbuhan dan Produksi Tanaman Selada (Selada (Lactuca sativa L. Var New Grand Rapids)}

Hasil analisis sidik ragam menunjukkan bahwa kombinasi Dosis Larutan AB Mix dan Media tanam pada umur $1 \mathrm{mst}, 2 \mathrm{mst}, 3 \mathrm{mst}, 4 \mathrm{mst}$, dan $5 \mathrm{mst}$ berpengaruh tidak nyata terhadap tinggi tanaman $(\mathrm{cm})$ sedangkan Jumlah daun (helai) dan Berat tanaman (g) berpengaruh sangat nyata pada uji Duncan $5 \%$.

Menurut Moerhasrianto (2011) pemberian nutrisi dengan konsentrasi yang tepat sangatlah penting pada hidroponik, karena nutrisi cair merupakan satu-satunya sumber hara bagi tanaman. Unsur hara makro dibutuhkan dalam jumlah besar dan konsentrasinya dalam larutan relatif tinggi.

Kedua parameter yakni tinggi tanaman dan jumlah daun tanaman memiliki hubungan yang sinergis. Jumlah daun berhubungan dengan pertumbuhan batang atau tinggi tanaman dimana batang tersusun dari ruas yang merentang diantara buku-buku batang tempat melekatnya daun. Sehingga dengan bertambah panjangnya batang akan menyebabkan jumlah daun yang terbentuk juga semakin banyak. Pertumbuhan tinggi tanaman terjadi akibat dari pemanjangan dan pertambahan ruas pada batang. Pemanjangan ruas terjadi karena adanya aktivitas pembelahan sel yang pada akhirnya menyebakan pertambahan jumlah sel.

Berdasarkan analisis sidik ragam pada hasil uji DMRT $5 \%$, Pengaruh interaksi pengaplikasian Larutan AB Mix dan Media tanam berpengaruh tidak nyata terhadap tinggi tanaman (cm) pada umur 1 mst, 2 mst, 3 mst, 4 mst dan 5 mst. Sedangkan pengaplikasian Larutan AB Mix dan Media tanam berpengaruh sangat nyata terhadap berat tanaman saat panen (g) dan jumlah daun pada umur 2 mst, 3 mst, 4 mst, dan 5 mst.

\begin{tabular}{lrr}
\hline OPTIMALISASI PEMANFAATAN & LAHAN & ZULKIFLI dan IDA ZULFIDA \\
SEMPIT MENGGUNAKAN & TEKNIK & \\
VERTIKULTUR & MIKROHIDROPONIK & \\
DENGAN MEDIA TANAM DAN PUPUK AB & \\
MIX PADA TANAMAN & SELADA & (Lactuca \\
sativa L.) &
\end{tabular}


Pada penelitian ini, kombinasi perlakuan larutan AB Mix pada taraf 500 ppm $\left(\mathrm{AB}_{0}\right)$ dengan Media tanam cocopeat $\left(\mathrm{M}_{1}\right)$ dianggap lebih baik dibandingkan dengan perlakuan larutan $\mathrm{AB}$ Mix pada taraf $750 \mathrm{ppm}\left(\mathrm{AB}_{1}\right)$ dengan media tanam arang sekam $\left(\mathrm{M}_{0}\right)$ terhadap Tinggi tanaman, Jumlah daun, dan Berat tanaman.

\section{Pengaruh Penerapan Teknik Vertikultur Mikrohidroponik dalam mengatasi permasalahan Lahan Sempit.}

Pada masa pandemi Covid-19 saat ini, sangat mempengaruhi mobilisasi masyarakat dan pola hidup masyarakat, diantaranya sulitnya untuk medapatkan bahan pangan yang sehat, maka teknik vertikultur mikrohidroponik memungkinkan masyarakat untuk bisa menanam langsung tanaman sayuran di pekarangan rumah. Penerapan teknik vertikultur hidroponik merupakan salah satu teknik dalam mengatasi permasalahan lahan sempit. Hal ini sesuai dengan pendapat Mindari W, dkk. (2019) yang menyatakan bahwa sistem tanam vertikultur merupakan cara tanam vertical. Media tanam campuran dari material tanah dan kompos yang ringan tidak membebani rak tanam. Kelebihan sistem vertikultur dan sistem hidroponik adalah efisiensi cahaya, udara, air dan nutrisi sehingga meningkatkan hasil usaha hingga mencapai 2-4 kali lipat.

Pada penelitian ini, teknik pertanaman secara vertikultur hidropnik mampu mengatasi permasalahan lahan sempit yaitu dengan volume area pertanaman yaitu $300 \mathrm{~cm} \times 50 \mathrm{~cm} \times 120 \mathrm{~cm}$ mampu dibudidayakan tanaman selada secara hidroponik dengan sistem DFT (Deep Flow Tehnique) sebanyak 96 tanaman dengan jarak antar tanaman $15 \mathrm{~cm}$ dan jarak antar pipa dalam instalasi $30 \mathrm{~cm}$ dengan 2 (dua) instalasi.

\section{KESIMPULAN}

Dari hasil penelitian ini, dapat ditarik kesimpulan sebagai berikut :

1. Pengaruh pengaplikasian Larutan AB Mix tidak berpengaruh nyata terhadap tinggi tanaman (cm) pada umur 1 mst, 2 mst, 3 mst, 4 mst, 5 mst, jumlah daun (helai) pada umur 1 mst, 2 mst, 3 mst, 4 mst, 5 mst, sedangkan berpengaruh nyata terhadap berat tanaman (g).

2. Pengaruh pengaplikasian Media tanam tidak Pengaruh pengaplikasian Larutan AB Mix tidak berpengaruh nyata terhadap tinggi tanaman $(\mathrm{cm})$ pada umur $1 \mathrm{mst}, 2$ mst, 3 mst, 4 mst, 5 mst, jumlah daun (helai) pada umur 1 mst, 2 mst, 3 mst, 4 mst, 5 mst, sedangkan berpengaruh nyata terhadap berat tanaman $(\mathrm{g})$.

3. Interaksi pengaplikasian Larutan $\mathrm{AB}$ Mix dan Media tanam tidak berpengaruh nyata terhadap tinggi tanaman $(\mathrm{cm})$ pada umur 1 mst, 2 mst, 3 mst, 4 mst, 5 mst, jumlah daun (helai) pada umur 1 mst, sedangkan berpengaruh nyata terhadap jumlah daun (helai) pada umur 2 mst, 3 mst, 4 mst, 5 mst, dan berat tanaman (g).

\begin{tabular}{lrr}
\hline OPTIMALISASI PEMANFAATAN & LAHAN & ZULKIFLI dan IDA ZULFIDA \\
SEMPIT MENGGUNAKAN & TEKNIK & \\
VERTIKULTUR & MIKROHIDROPONIK & \\
DENGAN MEDIA TANAM DAN PUPUK AB & \\
MIX PADA TANAMAN & SELADA & (Lactuca \\
sativa L.) &
\end{tabular}


Novianti, Nila, dkk. (2019). Pengendalian Kualitas Produk Selada Romaine Pada Sistem Tanam hidroponik (Studi Kasus Di UMKM Kebun Sayur, Kota Surabaya, Jawa Timur). Jurnal Sosial Ekonomi dan Kebijakan Pertanian. ISSN 2580-0566. 3(2): 131-149. November 2019.

Ramadhany, Anne Rizky, Sulistyo dewi Nur Wiyono, Kuswarini Kusno dan Lucyana Trimo. (2020). Analisis Kelayakan Usaha Budidaya Selada Krop di CV. Cantigi Desa Cikandang Kecamatan Cikajang Kabupaten Garut. Forum Agribisnis (Agribusiness Forum), Vol. 10 No. 1. Maret 2020; halaman 27-35. Bandung. 